\title{
MANUSCRITOS MEDIEVALES EN LA NOVELA ESPAÑOLA CONTEMPORÁNEA*
}

\author{
Antonio Huertas Morales \\ Universidad de Zagreb \\ antonio.huertas@uv.es
}

\begin{abstract}
Mi sono messo a leggere o a rileggere i cronisti medievali, per acquisirne il ritmo, e il candore. Essi avrebbero parlato per me, e io ero libero da sospetti. Libero da sospetti, ma non dagli echi dell'intertestualità. Ho riscoperto così che gli scrittori hanno sempre saputo (e che tante volte ci hanno detto): i libri parlano sempre di altri libri e ogni storia racconta una storia già raccontata. Lo sapeva Omero, lo sapeva Ariosto, per non dire di Rabelais o di Cervantes. Per cui la mia storia non poteva che iniziare col manoscritto ritrovato, e anche quella sarebbe stata una citazione (naturalmente). Così scrissi subito l'introduzione, ponendo la mia narrazione a un quarto livello di incassamento, dentro a altre tre narrazioni: io dico che Vallet diceva che Mabillon ha detto che Adso disse ${ }^{1}$.
\end{abstract}

Con estas palabras daba cuenta el recientemente fallecido Umberto Eco de cómo había recurrido al manuscrito encontrado para la composición de Il nome della rosa, novela con nombre propio dentro de la recuperación contemporánea de la Edad Media² ${ }^{2}$ El semiólogo italiano no solo ocultaba la voz del narrador tras un tópico del género, sino que además imaginaba una biblioteca borgiana en la que otro manuscrito, en este caso una segunda parte ficticia de la Poética de Aristóteles, dedicada a la comedia, iba a convertirse

* El presente trabajo se enmarca dentro del proyecto Parnaseo (Servidor Web de Literatura Española), referencia FFI2014-51781-P, concedido por el Ministerio de Economía y Competitividad.

${ }^{1}$ Umberto Eco, Il nome della rosa. Postille a Il nome della rosa, Milano, Bompiani, 1986, pp. 512513.

${ }^{2}$ Para la algunas consideraciones sobre la influencia de Umberto Eco en la narrativa de tema medieval española, vid. Antonio Huertas Morales, La Edad Media contemporánea, Vigo, Academia del Hispanismo, 2015, pp. 34-37. 
en eje de la trama: un códice cuyo contenido no puede ser desvelado, modelo ampliamente seguido por la narrativa occidental.

Su impronta, sin embargo, excede las ya clásicas pesquisas de Adso de Melk y Guillermo de Baskerville. Eco ha sido quien mejor ha anticipado y plasmado las sendas por las que iba a transitar la narrativa (y con ello no excluimos otras formas no literarias), planteando como una constante en sus novelas algunos de los problemas, miedos y paranoias actuales - pero también de esa nueva Edad Media posmoderna teorizada ampliamente a finales del siglo pasado ${ }^{3}$, vinculados a la palabra y la verdad, la palabra y la representación, la palabra y la creación, y que han convertido al manuscrito en protagonista de la narrativa histórica contemporánea. Baste recordar, solo como ejemplo, Il pendolo di Foucault, donde se unían las sociedades secretas, el ocultismo y la necesidad o la voluntad de creer, adelantándose al boom templario y los superventas pseudohistóricos, o Baudolino, sobre el mito del reino del Preste Juan, la creación por la palabra y las misivas apócrifas llegadas al Sacro Imperio ${ }^{4}$.

Justo cuando el libro impreso parece estar a punto de perder su hegemonía y la lectura en red o en soporte electrónico va ganando cada vez más adeptos, la literatura contemporánea muestra una mirada nostálgica y hasta reverente hacia el texto medieval, y centenares de novelas se vertebran sobre las obras de los siglos medios (u obras custodiadas en el medievo), ya sean reales o ficticias. El libro antiguo se reviste de un valor místico, mágico o esotérico que le devuelve sus dimensiones de obra sagrada, de palabra revelada, erigiéndose en objeto de devoción:

Yo, que amaba las bibliotecas tanto o más que a Farag (es un decir), quedé prendada de inmediato de aquella maravilla para el resto de mi vida. Sabía que era un amor imposible, que nunca sería mía, pero no me importó. Le entregué mi devoción eterna y mi corazón para siempre. Inhalé el aire lenta y profundamente para que aquel aroma a libro antiguo, a papel viejo, a madera, a tela, a vitela y a cuero inundara todos los rincones de mi cuerpo y me impregnara como si fuera un óleo sagrado. Nunca, nunca jamás podría mi tablet proporcionarme, ni siquiera fugazmente, un momento tan intenso como aquél (por muy cómodo que fuera para leer que, sin duda, lo era) . $^{5}$

${ }^{3}$ Vid., por ejemplo, Umberto Eco et al., Documenti su Il nuovo medioevo, Milano, Bompiani, 1973.

${ }^{4}$ Umberto Eco, Il pendolo di Foucault, Milano, Bompiani, 1988 y Baudolino, Milano, Bompiani, 2000. El italiano abordaría también la célebre impostura de los Protocolos de los Sabios de Sion en Il cimitero de Praga, Milano, Bompiani, 2010, y los límites entre realidad y ficción, esta vez en el ámbito periodístico, en Numero zero, Milano, Bompiani, 2015, su última novela.

${ }^{5}$ Matilde Asensi, El regreso del Catón, Barcelona, Planeta, 2015, p. 92. 
Huelga con echar un vistazo a las referencias bibliográficas para observar que bajo el título «El manuscrito / códice / pergamino / libro de...» se agrupa un buen número de novelas reconocibles desde el horizonte de expectativas del lector por la reiteración de sus ingredientes narrativos, y que algunos autores han visto el lado promocional de las intrigas en torno a un manuscrito, por lo que le han concedido un lugar preminente en su producción literaria. No obstante, no podemos hablar de uniformidad: en algunos casos, el manuscrito solo se menciona o describe, mientras que en otros accedemos a su contenido, que a veces ocupa capítulos o pasajes alternos y narra episodios presuntamente desconocidos de nuestro pasado. Tampoco se puede afirmar que, amén de su función, exista un rigor o interés histórico, filológico o paleográfico común: mientras que algunos incluyen detalladas descripciones e imágenes, como ocurre con el Manuscrito Voynich en El castillo de las estre$l l a s^{6}$, en otros casos hasta se llega a la confusión terminológica, como en El espejo de Salomón ${ }^{7}$, donde se usa el término «codicilo», y no «códice», para designar la crónica buscada por los protagonistas.

La mayoría de las propuestas narrativas suele decantarse por el modelo clásico de la novela histórica o por la variante de la novela de indagación histórica, que tendría en El club Dumas su exponente de mayor éxito en los años noventa (y en la que, por cierto, aparece fugazmente un profesor de semiótica en Bolonia que no puede ser otro que Umberto Eco $)^{8}$, si bien el lector puede encontrar experimentos narrativos meritorios, como el que nos presenta La reina de las tres muertes: en el siglo xix Ramón Nenclares escribe una novela sobre Juana la Beltraneja y a sus manos llegan una crónica portuguesa anónima del siglo XVI sobre Enrique IV y otros documentos, pero en realidad es Carlos Scott Saavedra quien fabula la vida de su pariente tras hallar casualmente sus papeles, pero en realidad es Laura, un personaje, quien escribe sobre Carlos, firma la contraportada y, en la novela, dialoga con José Guadalajara ${ }^{9}$.

Como en la abadía del norte de Italia imaginada por Eco, en la narrativa contemporánea ambientada en la Edad Media desfilan todos los actores del

\footnotetext{
${ }^{6}$ Enrique Joven, El castillo de las estrellas, Barcelona, Roca, 2007.

${ }^{7}$ León Arsenal, El espejo de Salomón, Barcelona, Minotauro, 2006.

${ }^{8}$ Arturo Pérez-Reverte, El club Dumas, Madrid, Alfaguara, 1993. Para la novela de indagación histórica, vid. Fernando Gómez Redondo, «La narrativa medieval: tipología de modelos textuales», en Reflexiones sobre la Novela Histórica, ed. de José Jurado, Cádiz, Fundación Fernando Quiñones-Universidad de Cádiz, 319-359; Antonio Huertas Morales, «La historia en la novela no histórica: Edad Media y thriller contemporáneo», en L'Edat Mitjana en el cinema i en la novel·la històrica», ed. de Josep Lluís Martos y Marinela Garcia Sempere, Alacant, Institut Interuniversitari de Filología Valenciana, 2009, pp. 317-336, y Antonio Huertas Morales, La Edad Media contemporánea, ob. cit., pp. 107-117.

${ }^{9}$ José Guadalajara, La reina de las tres muertes, Madrid, Neverland, 2009.
} 
manuscrito medieval: autores, copistas, iluminadores, bibliotecarios. El manuscrito, a veces coetáneo y otras veces compuesto mucho antes, guarda las palabras de la herejía o revelaciones sobre los orígenes del cristianismo, período con el que la Edad Media queda emparentada en el imaginario literario. En las novelas de indagación histórica, el manuscrito no solo cela secretos o testimonios del pasado, sino que es el portal a través del cual actualidad y medievo coinciden, dando la sensación al lector de acceder a tiempos pretéritos a través de las disciplinas contemporáneas. No es de extrañar, por tanto, que también filólogos y profesores universitarios, a modo de cicerones y expertos, y siguiendo el modelo de Indiana Jones, guíen al resto de los personajes y al lector por la Edad Media y sus supuestos secretos. Muchas veces heterodoxos o marginados por no comulgar con las versiones oficiales de sus disciplinas, estos docentes e investigadores se mueven entre la paleografía, la cábala, la alquimia, la gematría, la traducción de lenguas muertas, etc. En este contexto narrativo, algunos textos alcanzan nombre propio: aparecen manuscritos desconocidos o perdidos debidos a las plumas más insignes de nuestro pasado, se revela el significado esotérico de los clásicos medievales y se pone en cuestión la historia oficial a través de las versiones silenciadas.

Con el fin de ofrecer una explicación cabal para tanta relevancia, no se puede soslayar cómo la realidad sigue siendo motor de la ficción y cómo determinados acontecimientos se filtran en las páginas de la narrativa, atrayendo al lector. Si, como se comentará más adelante, el Codex Calixtinus tenía una relevante presencia en dos de los éxitos editoriales de Matilde Asensi ${ }^{10}$, su robo no pudo más que devolverle el protagonismo: "Comencé a imaginar esta novela el día 8 de julio de 2011, justo al día siguiente al que en rueda de prensa se diera cuenta de la desaparición, en circunstancias asombrosas, del Códice Calixtino [...] $\gg^{11}$. La mayoría de los manuscritos que encontramos en estas novelas están vinculados a hallazgos contemporáneos que han suscitado los más variopintos debates sobre el cristianismo (los manuscritos hallados en Qumran y Nag Hammadi, por ejemplo, o el «papiro de King»), de ahí su condición de palabra revelada y su relación con la divinidad.

Ofrecemos a continuación una clasificación de las funciones más comunes de los manuscritos (incunables en algunos casos) medievales en la narrativa española contemporánea, teniendo en cuenta que es difícil deslindar entre una categoría $u$ otra, puesto que en ocasiones se superponen y algunas

\footnotetext{
${ }^{10}$ Nos referimos a Iacobus, Barcelona, Plaza \& Janés, 2000 y Peregrinatio, Barcelona, Planeta, 2004. Esta última, oportuna «síntesis» de la primera, se convierte a su vez en una guía del peregrino a Compostela.

${ }^{11}$ José Luis Corral Lafuente, El Códice del Peregrino, Barcelona, Booket, 2013, p. 334.
} 
novelas vertebran su acción alrededor de varios textos; que este papel, en puridad, no pertenece solamente a los códices, sino que en otras ocasiones recae en un mapa, retablo u otro objeto; que, narrativa propiamente de superventas, no se puede restringir, en absoluto, a nuestras letras, y que los manuscritos de la novela contemporánea, si bien nos trasladan a la Edad Media en la mayoría de las ocasiones, no excluyen otros períodos ${ }^{12}$.

\section{$\mathbb{E} I$ manuscrito encontrado ${ }^{13}$}

Recurso típico de las novelas de caballerías parodiado por Cervantes en el Quijote, gozó de popularidad también en la novela histórica decimonónica, tanto por la influencia de Walter Scott en toda Europa como a través de la tradición literaria española y su impronta cervantina, si bien los escritores románticos no llegaron a captar o a emular las sutilezas de la parodia y el humorismo del autor del Quijote ${ }^{14}$. Se trata, por tanto, de un recurso ya manido, aunque tiende a parodiarse y a complicarse, difícilmente interpretable como garantía de credibilidad o de verosimilitud, sino más bien como un guiño al lector fiel, que agradece tener entre manos una marca genérica esperada y reconocible. Actualmente aparece vinculado especialmente al género testimonial de las memorias, en las que los grandes personajes de la historia

\footnotetext{
${ }^{12}$ Cfr. Glòria Sabaté y Loures Soriano, «El llibre medieval a la novel·la histórica actual», en L'Edat Mitjana en el cinema i en la novel·la històrica», ob. cit., pp. 501-509. Aunque nuestra tipología presente divergencias, las autoras ya señalaban perfectamente algunas de las claves más relevantes de la presencia del libro medieval en la narrativa contemporánea. Hemos ejemplificado ampliamente las distintas categorías, si bien, por la extensión del presente trabajo, no hemos podido incluir otros títulos estructurados en torno a la búsqueda y los secretos de un manuscrito, como los de José Guadalajara, Signum, Madrid, La Factoría de Ideas, 2004; Jorge Díaz Leza y María Jesús Leza. El manuscrito de San Florián, Fuenlabrada, Entrelíneas, 2009; Peter Haris, El secreto del peregrino, Barcelona, DeBolsillo, 2010, o Santiago R. Hernández Sáez, Jake Ryan y el manuscrito de Ricardo de Chartres, El Fantasma de los Sueños, 2015.

${ }^{13}$ Vid. Carlos García Gual, «Un truco de la ficción histórica: el manuscrito reencontrado», en 1616. Anuario de la Sociedad Española de Literatura General y Comparada, 10 (1996), pp. 47-60, o Ana L. Baquero Escudero, «Un viejo y persistente tópico literario: el manuscrito hallado», en Estudios Románicos, 16-17 (2007-2008), pp. 249-260.

${ }^{14}$ Vid., por ejemplo, los trabajos de Ana L. Baquero Escudero, «Cervantes y la novela histórica romántica», en Anales Cervantinos, 24 (1986), pp. 179-192, o de Ermitas Penas, «Discurso cervantino y novela histórica romántica», en Anales Cervantinos, 30 (1999), pp. 139-156. Celia Fernández Prieto, Historia y novela, poética de la novela histórica, Pamplona, Eunsa.1998, p. 102, resume magistralmente las atribuciones del narrador de la novela histórica decimonónica, caracterizado por «fingirse transcriptor o editor del manuscrito original que contiene el relato verídico de los sucesos (narraciones fenoménicas); presentarse como una figura del saber (histor) que transmite al lector las informaciones históricas extradiegéticas necesarias para el seguimiento y la cabal comprensión de lo narrado; desarrollar sus funciones metanarrativa e ideológica (comentarios sobre la fiabilidad del manuscrito que le sirve de fuente, contraste entre el pasado y el presente, comentarios o digresiones morales, filosóficas, etc.); situarse en el mismo plano temporal del lector, el presente, en relación al pasado de la historia».
} 
o quienes los acompañaron narran en primera persona sus propias experiencias, desdibujadas a veces por el filtro de los recuerdos. La verdad personal desplaza, por tanto, a la verdad documental de la historiografía ${ }^{15}$. Suelen presentar versiones acordes con la historia conocida, sin que los detalles alcancen el protagonismo, puesto que prima la indagación en el propio personaje. Se garantiza así una historia íntima y auténtica en los casos más logrados, mientras que en otros simplemente el manuscrito encontrado y las memorias que contiene son solo una frágil mascarada para encubrir una historia novelada en la que el protagonista es, en realidad, un mero cronista. El recurso contaría en 1990 con un aval bien popular (un autor superventas, Antonio Gala, y un galardón comercial, el Premio Planeta), El manuscrito carmesí, que nos presenta las memorias de Boabdil, redactadas en los papeles carmesíes de la Cancillería de la Alhambra, descubiertas en la mezquita de Karauín en 1931 y posteriormente desaparecidas hasta su hallazgo en una biblioteca de Rabat ${ }^{16}$.

En otros casos, se nos ofrecen versiones alternativas, bien como homenaje a un personaje histórico, para refutar la verdad oficial -la de los ganadores siempre- o como juego narrativo e historiográfico. Así ocurre cuando un narrador, que asociamos con el propio Muñoz Puelles, relata el hallazgo de manuscrito de Hernando Colón en las guardas de la Historia del nuevo mundo. El hijo del Almirante, sabiendo perdida la pugna por los derechos de su familia, pretende dejar constancia de su verdad y narra el último engaño de Colón, que aprovechó el fallecimiento de Bartolomeo Fieschi para fingirse muerto y viajar de nuevo a las Indias, con la esperanza de que su treta devolviera dignidades y posesiones a los suyos. Cuando Hernando viaje hasta Boriquén, conocerá el trágico final de su padre, cuyo cráneo exhumará y llevará a Sevilla, donde, como su manuscrito, quedará enterrado ${ }^{17}$.

Otro manuscrito encontrado nos dará a conocer la vida y la obra poética de Jorge Manrique, en este caso una «tercera versión, o quizás deberíamos decir adaptación, del original que escribiera "Pericón el Corto" en 1491, en consecuencia más actualizada si cabe, de la segunda que realizo Don Julián, sobre la primera de Don Pedro Jesús, entre 1948 y 1968». Dicha Crónica de Pericón el Corto y su Señor Don Jorge Manrique se debe al que fue bufón y compañero del poeta, a instancias de una alta personalidad anónima (Pericón se dirige, como Lázaro de Tormes o el buscón Pablos, a «vuestra secreta merced». Sabremos finalmente por la abadesa, Asunta Serra, que se trata de Luis Manrique, hijo de don Jorge). Las noticias que nos dará el enano Pericón no

${ }^{15}$ Vid. Fernando Gómez Redondo, «La narrativa medieval: tipología de modelos textuales», art. cit.

${ }^{16}$ Antonio Gala, El manuscrito carmesí, Barcelona, Planeta, 1990.

${ }^{17}$ Vicente Muñoz Puelles, El último manuscrito de Hernando Colón, Barcelona, Tusquets, 1992. 
carecen de relevancia: las veinticuatro primeras estrofas de las Coplas no son un planto por Rodrigo Manrique, sino por Guevara, amante del poeta, muerto en la batalla del Rincón de Haro (las relaciones homosexuales de Manrique provocarán que, hallado el texto durante el siglo xx, sea silenciado) y, además, forman parte de un plan mucho más ambicioso:

junto al poema hasta entonces desconocido, había otros trozos de papel con algunas notas muy dispersas y diversas de mi amo en las que hablaba de ampliar las COPLAS, pero no solo con este postrer poema, sino con otros más de los cuales debo reconocer que no tengo noticia alguna de su redacción, aunque sí de su intención y que debieron quedar repartidos entre Belmonte y Montizón, o donde entonces quisiera guardarlos la perturbada discreción de don Jorge, al menos Pericón el Corto es lo único que sabe y jura, por si acaso alguien anda buscando inquisiciones. Pretendía con ello don Jorge hacer unas extensas Coplas con las que semejarse a un Petrarca o a un Dante en sus «dezires» por demostrarle a la memoria de Guevara, como en Castilla éramos tan capaces cual aquellos italianos que su amigo harto admirara en desprovecho de los nuestros, lástima que Dios no diese suficiente tiempo para rematar con abundancia tanto talento ${ }^{18}$.

Buscando mayor grado de veracidad, la peripecia del manuscrito se puede trasladar incluso a otras zonas paratextuales menos frecuentes, como ocurre en Las cartas de Yago, novela sobre la Cruzada de los Niños, en cuya contraportada podemos leer:

Mi padre, fallecido hace pocos años, dedicó toda su vida al estudio de relatos del medioevo. Catedrático de Historia Medieval de la Universidad de Bristol, compaginó sus clases con la investigación, haciendo, muchas veces, que su profesión y su afición indagadora quedaran por encima de la familia. Cuando él murió, su legado consistió en miles de folios con crónicas, notas y conclusiones. Entre ellos, estaba la copia de una recopilación de cartas halladas dentro de una tinaja sellada, a principios de siglo, en las ruinas de la aldea de El-Carjetein, en el actual estado de Israel, por una expedición arqueológica inglesa a cargo de Sir Roger Williams ${ }^{19}$.

\footnotetext{
${ }^{18}$ Pedro L. Nuño de la Rosa, El enano, Alicante, Instituto de Cultura «Juan Gil Albert», 1995. Las citas corresponden a las páginas 206 y 174-175, respectivamente.

${ }^{19}$ Esteban Perelló Renedo, Las cartas de Yago, Madrid, Europa Viva, 2007.
} 


\section{E I manuscrito como g ía}

Una lectura atenta de los manuscritos medievales permite comprender los secretos que celan. El esquema básico es aquel en el que el libro constituye, en realidad, un conjunto de pistas, el mapa de un secreto (material, espiritual) oculto durante siglos, o que su sesudo estudio puede revelar el paradero, generalmente, de los grandes tesoros legendarios del medievo: el de los visigodos, escondido en la Península tras el saqueo de Roma; el que pusieron a salvo los cátaros que huyeron de Montségur, y el de la Orden del Temple, nunca hallado por Felipe IV el Hermoso. Un buen ejemplo es Iacobus, en la que Galcerán de Born, tras descubrir que las muertes de Clemente V, Felipe IV y Guillermo de Nogaret tienen firma templaria, recibe de Evrard, uno de los vengadores, las pruebas de los crímenes y un texto con claves para encontrar los tesoros de la Orden. Siguiendo el Codex Calixtinus, Galcerán emprende el Camino de Santiago en búsqueda de señales, enclaves y tesoros, hasta topar con los templarios supervivientes y el Arca de la Alianza ${ }^{20}$. A los Pirineos nos trasladan Los pergaminos cátaros, en la que, durante la invasión napoleónica, los protagonistas descubren una serie de pergaminos, escondidos por los cátaros ante la inminente caída de Montségur, que los llevan hasta el legendario tesoro de los bons homes -que, por cierto, incluye el que quizá sea el legado autógrafo de $M_{a n e}{ }^{21}$-. Por su parte, en El secreto del pergamino, el calor de la luz hace aparecer una combinación de ocho números oculta en un documento de comienzos siglo XIII sobre los costes de restauración de una ermita. Los protagonistas, seguidos por el Mossad y en contacto con los misterios y el simbolismo de la Orden del Temple, la herejía cátara y el ocultismo nazi, culminarán su búsqueda en el Midi francés: las averiguaciones los están llevando tras el tesoro escondido por los alemanes al finalizar la Segunda Guerra Mundial, así que será competencia de los organismos internacionales continuarlas ${ }^{22}$. Una doble búsqueda del tesoro templario de Aragón es la que tiene lugar en El anillo, en la que los protagonistas, con el anillo de los antiguos maestres templarios y con el manuscrito con las memorias del templario Arnau d'Estopinyà, llegarán hasta la iglesia de Santa Anna, para descubrir que el tesoro del Temple fue expoliado por los antiguos monjes del Santo Sepulcro ${ }^{23}$. Por su parte, El anticuario se vertebra sobre el hallazgo, en

${ }^{20}$ Matilde Asensi, Iacobus, ob. cit.

${ }^{21}$ Luis Melero, Los pergaminos cátaros, Barcelona, Roca, 2006.

${ }^{22}$ Xavier Musquera, El secreto del pergamino, Barcelona, Arborliber, 2004. Reeditado en Málaga, Corona Borealis, 2008.

${ }^{23}$ Jorge Molist, El anillo, Madrid, Martínez Roca, 2004. 
una biblioteca procedente de una masía señorial propiedad de los Bergués, una vieja familia catalana, de un dietario de finales del siglo xIV perteneciente al maestro de obras de la catedral de Barcelona, Pere Casadevall. En el manuscrito, que a medida que avanza pasa de ser dietario a crónica, el arquitecto dejó constancia de la iniciación que siguió para convertirse en el ocultador de la Piedra de Dios, perdida tras la destrucción del Templo de Salomón y que los judíos catalanes, sintiendo próxima su caída en desgracia, quisieron proteger $^{24}$. Más misterios templarios halla el lector en El sonido del clavicordio, en la que, sin saber al final si es ensueño o realidad, Ernesto Cervantes adquiere un castillo en Toledo de truculento pasado en el que habita el fantasma de su antepasado templario, Pedro Nuño de Cervatos, quien a punto estuvo de detener la conspiración contra el Temple y quiere que su historia, oculta en un viejo códice que reposa en las mazmorras, salga a la luz. El hallazgo del manuscrito, sin embargo, solo es la puerta de nuevas sorpresas, puesto que lo llevará al subsuelo de la catedral de Toledo, donde los templarios ocultaron el Grial-Baphomet: la cabeza del Bautista ${ }^{25}$.

Entre España y Rusia se sitúa El manuscrito de Avicena, texto compuesto por el médico y filósofo persa tras haber consultado la Gran Biblioteca, codiciado tanto por Al Qaeda, brazo armado de los Assassini, como por distintas agencias internacionales. Para hacerse con él, los protagonistas deberán seguir las pistas de una guía escrita en 1161 en el Monasterio de Silos, de la que solo el abad y el bibliotecario conocen la existencia ${ }^{26}$. En La conspiración del templo, llega a manos de Isaac Cohen un manuscrito de Samuel ben Ezra en el que se narra el episodio de los Fuegos de la Magdalena acaecidos en el siglo XV y en el que se hallan las instrucciones para encontrar el Pectoral del Juicio, que Eli Goodman, mecenas de Cohen, considera imprescindible para la construcción del Tercer Templo en el Monte Moria ${ }^{27}$. Por su parte, en El espejo de Salomón, para acceder al no menos ambicionado tesoro de los visigodos, Alejandra seguirá la pista de una traducción de 1847, debida a Augusto Ramos, de un manuscrito en ulfilano. El códice, una crónica compuesta por distintas manos que narra las vivencias de un grupo de visigodos tras la caída de Toledo, fue copiado por el templario Raimundo de Cagigal en 1172 de la Era Hispana y consta de 32 pergaminos, con tapas de madera, sin leyenda ni inscripción, pero sí iluminado ${ }^{28}$.

\footnotetext{
${ }^{24}$ Julián Sánchez, El anticuario, Barcelona, Roca, 2009.

${ }^{25}$ Francisco Zurita, El sonido del clavicordio, Amazon, 2015.

${ }^{26}$ Ezequiel Teodoro, El manuscrito de Avicena, Fuenlabrada, Entrelíneas, 2011.

${ }^{27}$ Peter Harris, La conspiración del templo, Barcelona, DeBolsillo, 2006.

${ }^{28}$ León Arsenal, El espejo de Salomón, ob. cit.
} 
En otros casos, el manuscrito medieval es también una guía, pero de iniciación, que lleva a los protagonistas a realizar una serie de pruebas para demostrar que son dignos de conocer y velar un secreto oculto. Es el esquema del que se vale Asensi en El último Catón, en la que la doctora Ottavia Salina, que trabaja el Archivo Secreto del Vaticano, deberá investigar, junto con el capitán Glauser-Röist y el profesor Boswell, la desaparición de los ligna crucis. A través de la iglesia de santa Lucía y con la Divina comedia como guía, los protagonistas accederán a un Purgatorio muy especial, donde tendrán que superar una prueba en cada una de las siete ciudades representantes de los pecados capitales: Roma, Rávena, Jerusalén, Atenas, Constantinopla, Alejandría y Antioch. Tras la última prueba, despertarán en Parádeisos: perseguidos, los staurofílakes, guardianes de la cruz, desarrollaron su propia civilización, y Dante, uno de los suyos, cifró el acceso en su Divina Comedia ${ }^{29}$. De la misma estructura de manuscritos (entre los que destaca la correspondencia entre María Paleólogo y Marco Polo) y pruebas de inteligencia, esta vez en torno a las Bienaventuranzas y en Har Meron, se volvería a servir Asensi en la siguiente aventura de la doctora Salina, El regreso del Catón, en la que los protagonistas colaboran con los multimillonarios Simonson para hallar unos osarios, entre los que se encuentra el de Jesús de Nazaret, mencionados en la carta del Patriarca Ortodoxo de Jerusalén, Dositheos, al Patriarca de Constantinopla, Nicetas, en el año $1187^{30}$.

\footnotetext{
${ }^{29}$ Matilde Asensi, El último Catón, Barcelona, Plaza \& Janés, 2001. Dante y la Divina Comedia han ocupado un lugar privilegiado en la narrativa contemporánea occidental. Mencionaremos solo algunos de los ejemplos más relevantes para el propósito del presente estudio. El superventas de Matthew Pearl, The Dante Club, Random House, 2003, ficcionaliza una serie de asesinatos que muestran similitudes con el Inferno dantesco y tienen lugar precisamente en el momento en que Henry Wadsworth Longfellow está a punto de publicar en Estados Unidos la traducción de la obra del florentino. El mismo modelo policíaco en torno a crímenes dantescos fue trasladado a la Venecia de 1756 por Arnaud Delalande, La piège de Dante, París, Grasset \& Fasquelle, 2006. Por su parte, en la novela de Nick Tosches, In the Hand of Dante, Brown, Little, 2002, la aparición del autógrafo de Dante desencadenará una oscura peripecia entre mafiosos por obtenerlo (mientras que se nos revelará que la intervención de Pietro Alighieri no fue la de mero soñador). A su vez, en la obra Francesco Fioretti, Il libro segreto di Dante, Roma, New Compton, 2011, descubrimos que Simone Bardi, humillado por el amor hacia Beatrice que Dante airea en sus obras, hace robar el autógrafo para destruirlo, pero Dante escondió los últimos cantos prudentemente antes de morir (la versión harto conocida que debemos a Boccaccio no es más, por tanto, que una invención). Esos cantos son los que busca el ex templario Bernard, que cree que el secreto templario llegó hasta Dante, e incluso sospecha que el florentino pudo haber sido maestre de la Orden. Finalmente, en la novela de Franco Paturzo, El libro perdido de Dante, Sevilla, Algaida, 2015, los protagonistas, durante la exhumación de los restos del florentino, hallan un mensaje para llegar hasta la biografía de Dante, la Vita Dantis de Louis Perrault, que a su vez contiene la pista para, en San Miguel Arcángel de Salon-de-Provence, hacerse con la Revelatio Dantis Comediae, que les servirá para desentrañar el secreto contenido en la Divina comedia. Así lograrán llegar hasta la bahía de Junafoi, donde de nuevo verso 67 del canto XXXI del Infierno se revela la clave para acceder hasta el tesoro cátaro, el Camino de perfección y el manuscrito de la Divina Comedia original, la esotérica Divina comedia cátara.

${ }^{30}$ Matilde Asensi, El regreso del Catón, ob. cit.
} 


\section{E I portal a otro mundo}

Si en la narrativa histórica el manuscrito es el depositario de incómodas revelaciones, de secretos ocultos o de versiones que cuestionan las crónicas conocidas, en los modelos híbridos con la fantasía y la ciencia ficción puede convertirse también en el portal a otro mundo, o en la clave para hallarlo y abrirlo, sea a través de la fórmula ritual o la ecuación matemática ${ }^{31}$. Así acontece en las obras de Óscar Esquivias, donde don Cosme Herrera, penitenciario de la catedral de Burgos, cree que el Purgatorio de Dante es un libro de viajes, la crónica del propio florentino, de modo que en la trilogía se plantea, en clave sobrenatural, el itinerario inverso de Dante Alighieri en la Divina Comedia. La obra del florentino será la puerta hacia un Purgatorio al que los protagonistas deciden entrar, a través del sepulcro del arcediano Pedro Fernández Villegas, mientras estalla la Guerra Civil española:

Primero, el libro de piedra que don Cosme había arrancado del sepulcro cambió de aspecto. De repente, como si se tratara de un juego de magia del Padre Pintado, había adquirido la apariencia de un libro real, con sus tapas aterciopeladas de color rojo.

- ¡Es la Divina comedia! —afirmó entonces don Cosme, con voz nerviosa-. ¡Es la obra completa traducida por Villegas!

El libro estaba en el suelo y parecía dotado de movimiento: tenía una especie de temblor que le hacía desplazarse a saltitos, como si fuera una rana. Luego sus tapas empezaron a agitarse y echó a volar con cierta torpeza de perdiz. El libro desprendía luz y se distinguía su trayectoria por las naves. Al igual que un pájaro despistado o una polilla encerrada en un farol, buscaba una salida sin lograrlo: chocaba con las verjas de las capillas, se elevaba y se atizaba contra las claves de las bóvedas, daba círculos en el crucero sin hallar un hueco que le permitiera escapar. Parecía ciego y desesperado. Varias veces cayó a plomo, pero en seguida volvía a las alturas. Su vuelo se fue haciendo cada vez más frenético, con aleteos furiosos. Al tiempo, se empezaron a oír unos golpes tremendos que procedían del subsuelo. La oscuridad se volvió casi absoluta y los faroles no iluminaban nada, pese a estar encendidos. Pronto se sintió una poderosa ráfaga de aire que olía a humedad. El libro entonces comenzó a planear elegantemente y finalmente dobló hacia la nave del transepto y se quedó allí detenido, a más de diez metros de altura ${ }^{32}$.

${ }^{31}$ Vid. Antonio Huertas Morales, «La Edad Media entre la historia y la fantasía: modelos del nuevo milenio», en Tonos digital. Revista digital de estudios filológicos, 26 (2014). [En línea]. Enlace: <https://www. um.es/tonosdigital/znum26/secciones/estudios-12-huertas_edad_media.htm> [Consulta: 12/04/2016].

${ }^{32}$ La trilogía de Esquivias está formada por Inquietud en el Paraíso, A Coruña, Ediciones del Viento, 2005; La ciudad del Gran Rey, A Coruña, Ediciones del Viento, 2006, y Llega la noche, A Coruña, Ediciones del Viento, 2007. La cita corresponde a la segunda, pp. 18-19. 
El lugar al que llegarán, en La ciudad del Gran Rey, sin embargo, poco tendrá que ver con el promontorio descrito por el poeta florentino, sino que se toparán con una ciudad demencial que guarda una engañosa semejanza con Burgos. Allí los protagonistas encontrarán la traducción y glosa del Purgatorio, realizada por Villegas y considerada perdida, donde se indica el procedimiento para regresar.

Por su parte, la saga Porta Coeli nos presenta un manuscrito, durante mucho tiempo custodiado en el monasterio de Santa Ceclina, que actúa como llave de un portal entre dos mundos. Se trata de una copia griega, en muy mal estado, de un original posiblemente egipcio, con curiosas ilustraciones de animales y plantas. En sus primeras partes habla de un paraíso anterior a la caída de los hombres, astrología, solsticios, etc., para acabar relatando la historia de un viajero que logró cruzar al otro lado y las instrucciones para abrir las puertas. En la primera entrega de la colección los protagonistas deberán recuperar el Porta Coeli y cerrar las puertas que llevan a la otra dimensión, si bien la persecución eclesiástica contra la Orden de Santa Ceclina provocará que acaben habitando ese otro mundo ${ }^{33}$.

Estos manuscritos, a pesar de su antigüedad, pueden no estar escritos en vitela, pergamino o papel, sino en metal dorado, como sucede en Los códices del apocalipsis, donde los protagonistas descubren máquinas que orbitan en el espacio creadas y puestas en el cielo por templarios, gnósticos, iluminados y alquimistas, según las instrucciones de aquellos seres que crearon nuestra civilización y que esperan regresar algún día a través de puertas provocadas por oscilaciones del universo que esas máquinas pueden mantener o cerrar ${ }^{34}$.

\section{E I manuscrito espejo}

Si en muchas ocasiones las pesquisas de los personajes los convierten en los caballeros de una quête iniciada siglos antes, y como sus antecesores medievales se dejan guiar o resuelven los misterios planteados siglos atrás, en otros casos el manuscrito es el espejo de la acción novelesca, reflejo contemporáneo de la obra medieval. Uno de los títulos más interesantes al respecto es Erec y Enide, en la que sus protagonistas reviven la acción del roman homónimo de Chrétien de Troyes: mientras Pedro y Myriam, pareja de enamorados que colabora con una ONG en Latinoamérica, afrontan los mismos

\footnotetext{
${ }^{33}$ Los títulos que nos interesan, por su ambientación medieval, son Susana Vallejo, Porta Coeli I. La orden de Santa Ceclina, Barcelona, Edebé, 2008 y Porta Coeli II. Cosecha negra, Barcelona, Edebé, 2009.

${ }^{34}$ Elio Quiroga, Los códices del apocalipsis, Barcelona, Tyrannosaurus Books, 2014.
} 
peligros y dificultades que los enamorados medievales, el catedrático de Filología Románica Julio Matasanz y su esposa Madrona, como Arturo y Ginebra una vez consumado el adulterio, esperan en La Alegría de la Corte ${ }^{35}$. También a una presunta obra de Chrétien nos remite Rosa Montero en El corazón del tártaro. Zarza, la protagonista, recibe una llamada que la informa de la puesta en libertad de su hermano, a quien su delación le costó siete años de cárcel. La vuelta de Nico remueve el pasado de Zarza hasta límites insospechados, y la editora planea una fuga irracional hacia ninguna parte hasta que logra enfrentarse a su propio pasado y reconciliarse consigo misma, sin temer a ese perseguidor cuya verdadera identidad nunca conocemos. Su periplo se produce mientras prepara una edición de lujo de El caballero de la rosa, de Chrétien de Troyes, obra descubierta en los años setenta, en el monasterio de St. Michael de Cornualles, por un joven medievalista británico llamado Harris. El relato, tal y como afirma Chrétien en su prólogo, parece arrastrar una maldición, que le valió a Harris ser repudiado por la comunidad científica incluso cuando Le Goff avaló la autenticidad del hallazgo. Rosa Montero detalla la impostura literaria de la ficticia obra de Chrétien, ubicando su acción en el ducado de Aubrey y su fecha de composición en torno a 1175, entre El Caballero de la Carreta y el Perceval. La obra estaría destinada a legitimar las pretensiones dinásticas de Edmundo Glasser, IX duque de Aubrey, quien, quizá descontento con la pieza, decidió mantenerla oculta. La obra narra la historia de venganza y muerte, y por eso Zarza la siente relacionada con su hermano, de los dos hijos de Thumberland, primer duque de Aubrey: el bastardo Edmundo, conocido como el Caballero de la Rosa, y Gaon, llamado Puño de Hierro, segundo conde de Aubrey. Sin embargo, una vez encauzado el nuevo rumbo de su vida, Zarza decide incorporar en su edición una versión distinta (¿un borrador de Chrétien o un texto para enmendar el original?) del final de la obra, hallado por Harris veinte años después y con una propuesta conciliadora $^{36}$.

\section{I a fortuna de la obra medieval}

Uno de los atractivos que tiene la narrativa histórica de tema medieval para los lectores contemporáneos es la posibilidad de reconocer los clásicos literarios presentes en los programas escolares. Entre el guiño metaficcional, la propuesta culturalista y el juego literario, desfilan por las páginas de las novelas históricas numerosos manuscritos que nos desvelan los secretos

\footnotetext{
${ }^{35}$ Manuel Vázquez Montalbán, Erec y Enide, Barcelona, Mondadori, 2002.

${ }^{36}$ Rosa Montero, El corazón del tártaro, Madrid, Espasa-Calpe, 2001.
} 
compositivos y autoriales de las obras que tanta tinta han costado a los expertos. El mejor ejemplo al respecto es el de La Celestina. En Melibea no quiere ser mujer, Rodrigo Vara habla a Fernando de Rojas de la existencia de un genial manuscrito. Al día siguiente, Vara aparece asesinado y Rojas encuentra en el lecho de la víctima el primer auto de una obra que considera maestra. Encandilado por ella, decide dar con su autor, que no es otro que Lisona, una prostituta de la que se enamora y a la que anima a continuar el texto. Entre los dos la obra ira tomando forma, tarea dificultada por la persecución de un inquisidor que cree al estudiante culpable de herejía y asesinato, y del que solo lograran deshacerse tras varias peripecias. Con la redacción acabada, Lisona marcha en su camino de libertad, dejando a Fernando solo y con el encargo de prolongar la relación sentimental de los personajes de la obra, que ellos no pudieron vivir ${ }^{37}$. En La judía más hermosa, de Fernando García Calderón, Susana de Susón, al pasar por La Puebla de Montalbán, se hospedará con la familia de Rojas. En sus conversaciones con la judía, Fernando, que se convertirá en su honesto cicerone, admitirá su vocación literaria, así como los motivos que lo impulsaron a estudiar Derecho: su familia y las necesidades económicas. Será Susana quien, al narrarle peripecias de su vida, le dé al bachiller el argumento de La Celestina:

La alegría de verdad, sincera, se la proporcionó un paquete traído desde la lejana ciudad de Burgos. Se lo remitía el impresor don Fadrique de Basilea y contenía un libro. Comedia de Calisto y Melibea, llevaba por título. Entre sus páginas halló una nota, anónima, que rezaba: «Para la mejor Melibea que nunca imaginé, con mi gratitud». No hacía falta firma. Sabía que procedía del inigualable Fernando de Rojas. Leyó con entusiasmo aquel volumen y lo cerró encantada. El bachiller había engrandecido la historia que ella le contase camino de Toledo, superándola en belleza y dramatismo. Susana no dudó en responder al envío con una carta, a entregar a su «legítimo dueño», en la que se deshacía en alabanzas y aportaba sugerencias y comentarios. Aquella correspondencia, siempre indirecta, daría como fruto una edición sevillana de la obra, Libro de Calixto y Melibea y de la puta vieja Celestina, que vio la luz meses después ${ }^{38}$.

En Escuchando a Filomena, el autor del Primer Auto se nos revela Gautier García, restaurador del alcázar de Talavera y consejero y confidente de la reina María de Portugal, que se basa en la existencia real de una «Celestina» salmantina:

\footnotetext{
${ }^{37}$ Juan Carlos Arce, Melibea no quiere ser mujer, Barcelona, Planeta, 1991.

${ }^{38}$ Fernando García Calderón, La judía más hermosa, Sevilla, Algaida, 2006, p. 476.
} 
Y, mire vuacé, tanta alegría me dio encontrarme a la Fandanga en Salamanca (y es que yo la quería una miaja, por paisana), que la llamé por este último nombre, Celestina, y acordándome del pontonero y su hija, quise componer en su honor una obrica nueva y bauticé a todos los personajes con mimbres de aquí y mimbres de allá. Llamé a uno Calisto, por ser muy apropiado de un mancebo ser bello y por significar Calisto bello en lengua griega, y por existir un hombre con este apodo en mi ciudad. A ella, Melivea, que es también vecina de Talavera y nombre de pastorcica. Al criado muerto Pármeno, que fue un golfín de los montes, de aquellos que murieron... ${ }^{39}$.

En El manuscrito de piedra, a la pluma de Hilario, cómplice de Celestina y responsable de la muerte del príncipe Juan y de fray Tomás de Santo Domingo, se debe el Primer Auto de La Celestina, que más tarde Rojas continuará y que el abogado Alonso Juanes, bajo el pseudónimo de Alonso de Proaza, editará:

El que más llamó su atención fue uno que parecía el inicio de una comedia. Su lectura le complació tanto que decidió completarla. Con ello pretendía cerrar un ciclo, aunque solo fuera de forma simbólica. Así que, unos meses después, ya en 1498, aprovechó los quince días de las vacaciones de Pascua para retocarla y continuarla hasta alcanzar un total de dieciséis autos. Según parece, la escribió en casa de unos parientes lejanos de Sabela, Tome González y Antonia Pérez, en la aldea de Tejares, que era donde se retiraban las mozas de la mancebía durante la Cuaresma, no muy lejos de la ciudad. La terminó justo el Lunes de Aguas, esto es, el siguiente al de Pascua, que era cuando expiraba el periodo de abstinencia y estas volvían a Salamanca, vitoreadas por los estudiantes, para bailar y comer el hornazo en las riberas del Tormes. Aunque la titulo Comedia de Calisto y Melibea, el personaje más importante de la obra resultó ser Celestina, que estaba inspirada en la vieja del mismo nombre que había conocido ${ }^{40}$.

\section{E I detonante}

En otras novelas el códice medieval no es el objetivo o el fin de las pesquisas, sino su desencadenante: el hallazgo de un manuscrito o su revelador contenido pueden originar variopintas aventuras. El pasado medieval despierta los más enconados sentimientos aún en la actualidad o hace saltar la chispa de truculentos planes. En El noveno círculo, el hallazgo de una carta manuscrita de Dante Alighieri, diario de viaje de los años en los que se movía entre Bolonia y Padua, cuando conoció a Giotto y empezaba a escribir su Convivio,

${ }^{39}$ Moisés de las Heras, Escuchando a Filomena, Barcelona, Muchnik, 2000, p. 188.

${ }^{40}$ Luis García Jambrina, El manuscrito de piedra, Madrid, Alfaguara, 2008, pp. 309-310. 
llevará al psiquiatra Emiliano del Campo a idear una serie de crímenes inspirados en la Divina Comedia, y Sebastiao Silveira, como Dante en su viaje de ultratumba, tendrá que internarse una madrugada del Jueves al Viernes Santo en el infierno desatado en Madrid ${ }^{41}$. Por su parte, en La sangre de los inocentes, Raymond de la Pallisière, conde d'Amis y devoto de la Crónica de fray Julián, compuesta a instancias de María de Aínsa para dar cuenta de los horrores de la cruzada, busca vengar la sangre de los cátaros derramada por la Iglesia en la Edad Media. En contacto con el Facilitador, Raymond se aliará junto con los integristas islámicos del Círculo para perpetrar un atentado múltiple contra la Iglesia: varios hombres de inmolarán el Viernes Santo para destruir las reliquias de la Cruz que se conservan en la Iglesia del Santo Sepulcro en Jerusalén, en la Iglesia de Santo Toribio en Santander y en la Basílica de la Santa Cruz de Jerusalén en Roma. Lo que los integrantes de Círculo ignoran es que el plan de los atentados incluye una segunda acción de la que ellos no formarán parte: el Facilitador pretende que Raymond, en contacto con Ylenia Milojevic, atente también contra las reliquias de Mahoma expuestas en el Pabellón Topkapi en Estambul, para desencadenar así una guerra entre el Islam y el Cristianismo.

\section{$\pi$ a verdad incómoda}

Siguiendo el modelo de Il nome della rosa, numerosos manuscritos medievales o custodiados en el medievo, reales o meramente ficticios, celan conocimientos o revelaciones que, en caso de ser divulgados, pueden resultar incómodos para alguien. El modelo más manido, reproducido hasta el hartazgo, es el de los secretos que «pueden socavar los cimientos de la civilización tal y como la conocemos o, al menos, el poder de la Iglesia», si bien la información oculta puede ser de la más diversa índole. Los protagonistas, que suelen acabar convirtiéndose en custodios del manuscrito y sus protectores, arriesgan la vida en una quête reveladora, perseguidos por toda suerte de órdenes, históricas o puramente inventadas, que ansían también el manuscrito. Así ocurre en El enigma del Codice Bardulia, inspirada en el hallazgo de los Cartularios de Santa María de Valpuesta, donde la aparición de un antiguo manuscrito, el texto más antiguo en castellano y en eusquera hallado hasta la fecha, puede resultar fatal, durante el cambio de gobierno en Euskadi, para la Fundación Ikastuna, que quiere impedir que salga a la luz y se cuestionen las aspiraciones nacionalistas vascas:

${ }^{41}$ Fernando S. Llobera, El noveno círculo, Barcelona, Planeta, 2005. 
-Espera que llegue al final, hombre -reprochó ella interrumpiéndole-, y lo entenderás todo. Hasta lo que yo sé, en el manuscrito se hallan las más antiguas palabras escritas en una lengua eusquera evolucionada y conformada gramaticalmente, y compartida, en ese periodo alto medieval, por algunos grupos de caristios, autrigones, várdulos y vascones -continuó Garbiñe, engolando la voz-; pero, para sorpresa... y desagrado, de mis jefes de la Fundación, expresan el compromiso de todos esos pueblos del norte con el espíritu de la Hispania total romana bajo el manto de una ley propia. El códice original parece narrar un pacto de vascones y várdulos que llegan a unas tierras donde otros pueblos hispano-romanos están diezmados por los musulmanes... Los pocos caristios y autrigones que quedan se les unen en esa misión... que no deja de ser un auténtico pacto por España. ¿Entiendes? ${ }^{42}$

Incómodo, además de un desagradable contratiempo, sería para Isabel y Fernando que Juan de Oviedo encontrara, guiado por los borradores con pistas que le ha dejado Lope de Mayorga antes de desaparecer, el testamento de Enrique IV. En su lecho de muerte, al que presumiblemente lo ha llevado el veneno, el monarca podría haber confirmado a Juana como la legítima heredera, pero los tentáculos de Febus, cabeza de la conspiración que pretende poner a Isabel en el trono de Castilla, se adelantarán al secretario de Juana la Beltraneja ${ }^{43}$.

Los templarios, por su contacto con Tierra Santa, y dentro del proceso de recuperación y mitificación en el que se han visto inmersos en las últimas décadas, se han convertido en guardianes de todo tipo de manuscritos y arcanos, proyectando casi, contra todo rigor histórico, la imagen de una orden de letrados amanuenses más interesada en los misterios del scriptorium que en las virtudes de la espada. Numerosos son los ejemplos. En La sombra del templario, Guillem de Montclar sigue la pista de los manuscritos que su mentor ha llevado a Barcelona desde Tierra Santa. Tras ellos van también esbirros papales y espías angevinos, entre los que se encuentra La Sombra, traidor al Temple. En manos de Guillem quedarán los misteriosos documentos y también la decisión de esconderlos para siempre: contienen pruebas de la naturaleza humana de Jesucristo $^{44}$. Por su parte, en La llave de oro, cuarta entrega de la «saga templaria» de Masot, la Inquisición recibe información sobre el paradero del texto sagrado de los cátaros, una versión en lengua de Oc del Apocalipsis de San Juan que fue salvada de Montségur, y tras ella irá también la Orden del Temple, aunque con recelos de su verdadera existencia. La trama, una venganza en

\footnotetext{
${ }^{42}$ Álvaro Moreno Ancillo, El enigma del Códice Bardulia, Barcelona, ViaMagna, 2010, pp. 88-89.

${ }^{43}$ José Guadalajara, Testamentvm, Madrid, La Factoría de Ideas, 2005.

${ }^{44}$ Núria Masot, La sombra del templario, Barcelona, Roca, 2004.
} 
realidad, ha sido planeada por Adalbert de Gaussac, último poseedor del manuscrito, un faidit que sufrió los desmanes del inquisidor Acard de Montcortés y sus esbirros ${ }^{45}$. En El gran arcano, aparecen finalmente los bifolios que completan el manuscrito de las actas del proceso inquisitorial al templario Jean de Voisins hallado diez años antes bajo el suelo del coro del monasterio de Santa María la Real de Las Huelgas. Los protagonistas, con la ayuda de un extraño libro relacionado con el manuscrito burgalés, y amenazados por la sociedad Asmodeo, recorrerán Burgos, Ucero, París, Couiza, Rennes-le-Château y Roma hasta descubrir su parentesco con Jesucristo y la pertenencia de sus progenitores a una sociedad, heredera espiritual de los templarios, que necesita los bifolios perdidos para descubrir y proteger el Gran Arcano, lugar en el que se encuentra la tumba de Cristo y el Libro sellado de Daniel, secreto del que también pretende apoderarse la actual Inquisición, pero con muy distintos fines ${ }^{46}$. En La serpiente roja, que parte del mismo material que The Da Vinci Code, Oficus, el Temple oculto, sigue vivo y vela por la protección del Evangelio de Andrés, donde se guarda la fecha del fin del mundo según los cálculos del mismísimo Jesucristo ${ }^{47}$. Finalmente, La reina oculta parte del asesinato, en 1208, del legado papal Pere de Castelnou, quien portaba unos manuscritos peligrosos para la Iglesia: los documentos son el testimonio de que Bruna, la protagonista, es la descendiente de Cristo con la sangre más pura, destinada a desposarse con el rey Pedro II, gran maestre de Sion. Será por ello que la joven destruirá los legajos para eliminar las pruebas de su identidad y poder casarse con el trovador al que ama ${ }^{48}$.

Secretos bíblicos son los que contiene también el Codex Calixtinus. El año 2011, Patricia Veri y Diego Martínez son contratados por Jacques Roman para robarlo aprovechando la conmemoración del octavo centenario de la consagración de la catedral de Santiago de Compostela. El códice custodia arcanos apocalípticos que los sectores más conservadores de la Iglesia quieren poseer: en el interlineado de la Guía del Peregrino, los folios numerados del 192 al 207, con una tinta especial invisible al ojo humano, Aimeric Picaud copió el texto en griego de Evangelio de Santiago el Mayor para que no se perdiera. El texto, traído por cruzados hasta Galicia y cuya custodia dio gran

${ }^{45}$ Núria Masot, La llave de oro, Barcelona, Roca, 2006.

${ }^{46}$ Paloma Sánchez-Garnica, El gran Arcano, Barcelona, Plaza \& Janés, 2006.

${ }^{47}$ Peter Harris, La serpiente roja, Barcelona, DeBolsillo, 2008. Precisamente a la impostura, burla o gran engaño de Pierre Plantard y la Prieuré de Sion, entre cuyas peripecias se incluía el presunto hallazgo o posesión de manuscritos y genealogías que se remontaban al medievo, debemos buena parte de esta narrativa. Vid. Antonio Huertas Morales, «El Priorato de Sión. Presencia del mito en la narrativa española, en Monographic Review, XXVII (2011), pp. 101-117.

${ }^{48}$ Jorge Molist, La reina oculta, Madrid, Martínez Roca, 2007. 
poder e influencia al obispo Gelmírez, atenta contra los pilares del cristianismo, al negar la divinidad de Jesucristo, la Trinidad y la virginidad de María. Por ello, Roman y los suyos, que se consideran los herederos de la verdadera Iglesia de Cristo, destruirán el Codex y, para evitar sorpresas futuras con la policía, también a quienes participaron en su robo ${ }^{49}$.

Entre tanta novela «historioclónica» ${ }^{50}$, tanto evangelio aparecido y tanto secreteo peligroso, no es de extrañar que algunas novelas, emulando los tópicos más exitosos, recurran a la parodia. Así sucede en Albada del viento, donde su narrador, homónimo del autor y no poco aficionado al alcohol, rememora la etapa más desconcertante de su vida, cuando heredó un misterioso manuscrito que acumulaba la sabiduría de las civilizaciones anteriores y tenía poder para doblegar voluntades. El texto, que había pasado por las manos de San Pedro, Jacques De Molay, Vasari, Napoleón, Lenin y Hitler, era codiciado por la Iglesia, el Mossad y La Entidad, que pretendía instaurar el IV Reich. Raúl destruyó el manuscrito, si bien ignoraba que, en 1457, unos desconocidos se aprovecharon de las necesidades económicas de Gutenberg para ordenarle realizar una decena de copias ${ }^{51}$.

Por otra parte, ahora que la editorial burgalesa Siloé prepara su edición facsímil, ocupa un puesto especial a este respecto el desconcertante y misterioso Manuscrito Voynich. Aunque su datación siga siendo motivo de discusión y se pueda retrasar hasta el siglo XVI, tanto la atribución a Roger Bacon por parte de alguno de sus primeros estudiosos como su presencia en novelas ambientadas en la Edad Media -el manuscrito aparece en manos del filósofo cretense Nikos Pagadakis en Las puertas del paraíso ${ }^{52}$ - nos permiten incluirlo en el presente trabajo ${ }^{53}$. En El castillo de las estrellas, el Manuscrito Voynich parece guardar pruebas de la intervención directa de Dios en la evolución del hombre, por lo que los seguidores del Diseño Inteligente pretenden desvelarlo, en una peripecia que se remonta a Kepler y los jesuitas ${ }^{54}$. La obra de Enrique Joven supone un intento por aunar texto e imagen, dado que es de los pocos títulos que incluyen reproducciones de las ilustraciones de los manuscritos (la inmensa mayoría solo menciona y describe las miniaturas) y las aprovechan para el desciframiento de los enigmas. En la saga de Alexander

\footnotetext{
${ }^{49}$ José Luis Corral Lafuente, El Códice del Peregrino, ob. cit.

${ }^{50} \mathrm{El}$ adjetivo, que aparece en la novela La Orden Voynich, que comentaremos más adelante, nos parece ilustrativo y por ello lo incluimos.

${ }^{51}$ Raúl Vela Larraz, Albada del viento, Amazon, 2014.

${ }^{52}$ Enrique Murillo Llerda, Las puertas del paraíso, Madrid, Martínez Roca, 2006.

${ }^{53}$ Vid. Jacobo Siruela, Libros, secretos, Girona, Atalanta, 2015.

${ }^{54}$ Enrique Joven, El castillo de las estrellas, ob. cit. El Manuscrito Voynich volverá a tener una importancia relevante en otra obra del autor, El templo del cielo, Barcelona, Roca, 2012.
} 
Copperwhite, aparece el original del Manuscrito Voynich, compuesto mucho antes de lo que los expertos dictaminan, en el maravilloso templo erigido por Apolonio de Pérgamo (si bien parece ser que fue Arquímedes el primero que descubrió sus secretos), que se valió de sus conocimientos para su construcción. El códice servirá para hallar el oro escondido por los aztecas e incluso para retener entre los vivos a los moribundos, de ahí que haya quien quiera que sus muchos secretos no sean revelados ${ }^{55}$.

Tampoco el Manuscrito Voynich iba a librarse de la parodia: en La Orden Voynich, que se inicia como remedo de The Da Vinci Code, y en la que el escritor Juan B. se ve inmerso en una irracional aventura que lo lleva a volver de entre los muertos, el Libro de la Vida, codificado por Leonardo en un lenguaje secreto que daría lugar al Manuscrito Voynich, es el compendio de saberes de una Orden que ha incluido entre sus miembros (treinta y tres elegidos, como las páginas que le faltan al manuscrito) a personalidades como Durero o Leonardo y que está en condiciones de lograr la Gran Obra ${ }^{56}$.

Finalmente, frente a la Edad Media entendida como media tempestas, como época oscurantista y de atraso, el libro medieval puede ser portador de valores de cambio. En El noveno libro se narran las hazañas de Aurora, quien en 1817 regresa a España llamada por los constitucionalistas gaditanos, que pretenden recuperar el noveno libro escrito por el obispo Juan Arias Dávila y publicado por Juan Parix en el siglo Xv, en el que se expone la necesidad de la mujer en el estado y con el que pretenden legitimar una constitución que ampare a las mujeres:

-Y qué mejor garantía para incorporar a la mujer a la revolución que ese libro del obispado indultado por un Papa? -retomó el anciano-. No sabemos si el pobre Inocencio VIII llegó a leer este noveno libro impreso por Parix, pero sí sabemos que absolvió al obispo Arias Dávila. Con ese libro en nuestro poder no habrá rey ni Papa que niegue los derechos de la mujer. Ni siquiera Fernando VII se atreverá a negarlo. Necesitamos el libro. La necesitamos a usted y a todas las mujeres de España para culminar nuestra revolución por la libertad. ¡Viva la libertad! ¡Viva la Constitución! -retumbó la biblioteca ${ }^{57}$.

${ }^{55}$ La trilogía, conocida como Misterios del Manuscrito Voynich, está compuesta por La vértebra de Dios, Amazon, 2013; El templo de los mil cristales, Amazon, 2014, y Las delicias del mal, Amazon, 2014.

${ }^{56}$ Alejandro Párraga, La Orden Voynich, Madrid, Bubok, 2013.

${ }^{57}$ Mikel Alvira, El noveno libro, Bilbao, Beta, 2006, p. 57. 


\section{E I manuscrito mğ co}

Como hemos comentado más arriba, en la década de los noventa El club Dumas tuvo una notable acogida entre los lectores, también con su versión cinematográfica. En la novela del académico, es Varo Borja quien, entre la iluminación y la locura, pretende invocar a Lucifer mediante las láminas del único ejemplar existente del Libro de las Nueve Puertas del Reino de las Sombras, salvado de la hoguera del Santo Oficio a mediados del siglo XVII, a diferencia de su impresor, Aristide Torchia, que perecería en las llamas. Aunque la época de la novela de Reverte exceda el ámbito del presente trabajo, el imaginario resultaba suficientemente atractivo para ofrecer otras plasmaciones en las que, entre la incredulidad de los personajes y la fuerza de leyenda, el manuscrito medieval se vuelca hacia lo diabólico o terrorífico, donde no faltan referencias a obras clásicas del género, como el Necronomicón ${ }^{58}$. Así ocurre en Las puertas del mal, donde, en 1276, en medio de las revueltas e insurrecciones en las tierras de un Jaume I viejo y enfrentado con su hijo Pere, Miró d'Esquenat pretende usar el presunto poder de El bestiario del Unicornio, copia de un antiguo manuscrito traído de Armenia por los cruzados del que se hicieron varias copias. Una de ellas, guardada en el monasterio de Sant Pere de Rodes, fue robada por quien pretende abrir las puertas del mal a través de dos series de asesinatos ${ }^{59}$.

Más allá del poder que pueden otorgar a su poseedor, en muchas ocasiones su misma existencia es prodigiosa. El libro se vuelve divino, o maligno, y es capaz de portentos en su misma materia. De este modo, en La tumba de Lunete, el gran secreto perseguido por los templarios y hallado por Alvar, miembro de una orden heredera, se custodia en un libro que no puede destruirse (acaba matando a quien lo intenta) y que parece alimentarse de la sangre de quienes lo pretenden ${ }^{60}$. Algo semejante sucede con El códice negro, un manuscrito maldito del siglo XI guardado en el museo parroquial de la basílica de Santa María en Castelló d' Empúries que narra la ambición de Wifredo de Berga y su búsqueda de Excalibur. Las páginas, completamente negras, solo

\footnotetext{
${ }^{58}$ El grimorio y su autor, Abdul Alhazred, creación de H. P. Lovecraft, aparecen en la obra de Juan Eslava Galán, Guadalquivir, Barcelona, Planeta, 1990, donde se afirma que fue vertido al latín por el templario aragonés Berenguer de Peramola, miembro de Lámpara Tapada, una organización clandestina que pretendía la sinarquía universal.

${ }^{59}$ Núria Masot, Las puertas del mal, Barcelona, Roca, 2007.

${ }^{60}$ Santiago Pisonero, La tumba de Lunete, Bilbao, Cuatroas, 2001. Otra edición en Bilbao, Verbigracia, 2003.
} 
se vuelven legibles ante aquellos que desconocen el pasado de la región, a la par que acababan enloqueciendo a sus lectores ${ }^{61}$.

Manuscritos que ofrecen una versión alternativa de la historia o, como guiño metaliterario, explican el proceso de creación de los clásicos del canon medieval. Códices que, casi un milenio después, guían a los protagonistas. Textos que conducen a un tesoro, a otro mundo o dimensión (Edad Media histórica frente a Edad Media fantástica: a fin de cuentas el imaginario de los universos postapocalípticos mucho le debe al mundo feudal) o a un secreto que puede hacer que se tambaleen los pilares de una civilización. Obras escondidas, codiciadas, celadas, que deben ser conseguidas a cualquier precio, descifradas, ocultadas de nuevo, destruidas. A partir de la tipología expuesta, y como conclusión, sería necesario apuntar cómo la literatura contemporánea ha devuelto al manuscrito medieval su estatus de palabra revelada, de verdad y de objeto de culto, pero no siempre desde pretensiones historicistas, en búsqueda de una reconstrucción de la vida en torno al scriptorium o del universo teocéntrico del hombre medieval y su relación con la palabra. La omnipresencia del códice medieval tiene más que ver con nuestro presente que con cualquier pasado: es precisamente la verdad resquebrajada posmoderna, sobre todo en su trascendencia, la que hace que traslademos revelaciones y descubrimientos contemporáneos a un tiempo popularmente considerado, si bien oscuro y misterioso (oscuros secretos guardados en más oscuras bibliotecas custodiadas por mucho más oscuros personajes), también estable en sus convicciones. De ahí también que, al revisar las creencias religiosas y el pasado de sus instituciones, regresemos a ese medievo que seguimos viendo como fanático, y que percibamos una relación de amor y odio semejante hacia la palabra escrita: en la Edad Media porque no se tenía acceso; hoy, porque consideramos que nuestro acceso es relativo, insuficiente, manipulado ${ }^{62}$. Basta con observar solo el revuelo paranoico suscitado por la divulgación literaria de los hallazgos de Qumran y del Mar Muerto, con su culmen en The Da Vinci Code y toda la narrativa templaria posterior en torno a los manuscritos de los que la Orden sería custodia, lo que nos da una imagen clara de la relación del hombre contemporáneo y la palabra ${ }^{63}$.

${ }^{61}$ José Hernández García, El códice negro, Amazon, 2012.

${ }^{62} \mathrm{Vid}$. Sabaté y Soriano, «El llibre medieval a la novel·la histórica actual», art. cit., p. 502.

${ }^{63}$ Para tener una imagen cabal de las dimensiones del fenómeno «Da Vinci», así como de los sentimientos, dudas y conflictos que originó, vid. Juan Manuel Mora, La Iglesia, el Opus Dei y El Código Da Vinci, Pamplona, EUNSA, 2009. 
Los manuscritos, en su exclusividad, ofrecen versiones únicas porque solo única puede ser la verdad. Cuando llegue la imprenta, el saber se extenderá y democratizará, pero se abrirá la puerta a que toda creencia sea relativa, parcial o escamoteada:

- ¿No te das cuenta, Johann? Ese es el motivo; por eso es por lo que merece la pena hacer este libro y todos los del mundo. Estoy cada vez más convencido de que la máquina necesitaba ser inventada; yo solo he sido el canalizador de esa necesidad. Un mundo lleno de libros, ¡de todo tipo y en cualquier lugar! Ese es el mundo que quiero para mi hija: un mundo donde la verdad esté al alcance de todos ${ }^{64}$.

Recibido: 15/04/2016

Aceptado: 25/06/2016

${ }^{64}$ Eduardo Roca, El taller de los libros prohibidos, Madrid, Martínez Roca, 2011, p. 635. 
$\cos 8$

\section{MANUSCRITOS MEDIEVALES EN LA NOVELA ESPAÑOLA CONTEMPORÁNEA}

Resumen: Si el recurso del manuscrito encontrado formaba parte de la novela histórica desde su configuración decimonónica, heredero de aquellas crónicas que poblaban las novelas de caballerías, a partir de Il nome della rosa, de Umberto Eco, el manuscrito se ha convertido en el protagonista de la narrativa contemporánea, y no solo de tema medieval. Aunque en la mayoría de casos se trata de códices que custodian información que podría socavar el orden mundial, y por eso deben seguir velados, existen multitud de posibilidades, como se sistematizará en las siguientes páginas, que pretenden explicar, además, a qué se debe tan notable presencia.

Palabras Clave: Manuscrito. Edad Media. Novela histórica. Novela contemporánea.

\section{Medieval Manuscripts in the Spanish Contemporary Novel}

ABSTRACT: The literary device of the «found manuscript», stemming from the ancient chivalric novels, was deployed by some nineteenth-century authors of historical novel. Also, since Umberto Eco's Il nome della rosa, manuscripts have become important characters in modern fiction. In these pages I intend to show the possible reasons for the frequent presence of manuscripts in this kind of novels. Some of these manuscripts, amongst other possibilities, contain information that could subvert the world order.

KeYwords: Manuscript. Middle Ages. Historical Novel. Contemporary Novel. 